\title{
Thai Pre-service Teachers' Aspects of Epistemology and Cognitive Processes for Providing Scientific Inquiry Activities
}

\author{
Jirakan Yuenyong
}

Khon Kaen University Demonstration School, Khon Kaen, Thailand

Jiraporn Tupsai

Science Education Program, Faculty of Education, Khon Kaen University, Thailand Khon Kaen University Demonstration School, Khon Kaen, Thailand

Chokchai Yuenyong*

Science Education Program, Faculty of Education, Khon Kaen University, Thailand Corresponding Author Email: ychok@kku.ac.th

\section{Doi:10.5901/mjss.2015.v6n2p465}

\section{Abstract}

The study aimed to examine Thai pre-service teachers' aspects of epistemology and cognitive process for providing scientific inquiry activities. Methodology is qualitative research. The research will interpret Thai pre-service teacher existing aspects of providing scientific inquiry activities through framework of Chinn \& Malhotra (2002) epistemology and cognitive processes of scientific inquiry. Participants included 15 science pre-service teachers who enrolled for teaching practices in schools for one year, in Thailand. The questionnaire of Providing Activities for Scientific Inquiry (QASI) and interviewing were tools for interpreting science pre-service teacher existing ideas of providing activities for scientific inquiry. The findings revealed that the most of participants perceived few aspects of cognitive process of scientific inquiry when they gave the ideas of using computer-supported for science teaching. Only three of six aspects of epistemology of scientific inquiry were found from science pre-service teachers' ideas. These included responses to anomalous data, purpose of research, and theory-data coordination.

Keywords: science activities, science, scientific inquiry, pre-service teacher

\section{Introduction}

It could be mentioned that goal of Thai science education considered the scientific literacy. The goal was focused on emphasizes the scientific knowledge, the nature of science, and the relationship between science technology and society. However, it seemed that Thai education acting only concerned on students' scientific achievement rather than learning science as a way of knowing. Thai science teacher research, articles, national tests, and teaching and learning showed little concerned about science as a way of knowing. (Yuenyong \& Narjaikaew, 2009). In order to obtain the goal of Thai science education, students should experience inquiry in science classrooms. Science learning as inquiry could give chance students to construct meaning of scientific concepts and also learn about the nature of science and develop scientific ways of thinking (Asay \& Orgill, 2010).

Although teachers perceived the potential benefits to using inquiry in a science classroom, however, it seemed to be challenged to implementing inquiry in classroom (Abd-El-Khalick et al. 2004; Crawford 2000; Krajcik et al. 1998; Lee \& Songer 2003). Teachers have a number of difficulties to implementing inquiry in the classroom. They worried about not having control over their classrooms during inquiry activities. There is not enough time to cover the authorized curriculum through inquiry. Or, even students are not capable of carrying out inquiry projects experiences (Asay \& Orgill, 2010). In order to provide powerful chance of scientific inquiry, teachers should gain knowledge and skills of providing scientific inquiry activities.

To clarify the continuum of scientific inquiry, the scientific reasoning is the central issue of distinguishing. It found that given scientific inquiry tasks in schools could not encourage students to give scientific reasoning. The scientific inquiry tasks should provide cognitive processes to engage in real scientific research. The epistemology and reasoning 
processes of authentic science needed to be taken into account in the tasks (Chinn \& Malhotra, 2002).

\section{Literature Review}

This study will adopt Chinn \& Malhotra (2002) epistemology and reasoning processes of authentic science as framework of clarifying pre-service teachers' existing ideas of computer-supported for scientific inquiry.

\subsection{Cognitive Processes of Scientific Inquiry}

The essences of cognitive processes given in an inquiry task could be label which one is the authentic scientific inquiry. Chinn \& Malhotra (2002) categorized the inquiry tasks into 4 types depends on cognitive processes are needed in the tasks. These included authentic inquiry, simple experiments, simple observations, and simple illustrations. They discussed key differences in cognitive processes of those four types of tasks through six of the elemental cognitive processes. These included generating a research question, designing a study to address the research question, making observations, explaining results, developing theories, and studying others' research.

Chinn \& Malhotra (2002) explained each six of the fundamental cognitive processes as follows. First, the details and quality of generating research questions could be distinguish between simple inquiry tasks and authentic inquiry. In simple inquiry tasks, students are told what the research question is. In authentic inquiry, scientists must develop and employ strategies to figure out for themselves what their research question is. Second, the details of designing studies could be distinguish between simple inquiry tasks and authentic inquiry. Chinn \& Malhotra (2002: 183 - 184) explained 4 sub-processes of designing studies including selecting variables, planning procedures, planning procedures, and controlling variables. Third, quality of making observation could be distinguish between simple inquiry tasks and authentic inquiry. In authentic research, scientists often employ special methods to guard against perceptual bias. However, students may try to make measurements more precise with little if any discussion of the issue of perceptual bias. Fourth, details of explaining results will be distinguish between simple inquiry tasks and authentic inquiry. In authentic science may considered several important aspects of explaining results including transforming observations, finding flaws, indirect reasoning, generalizations, and types of reasoning. Fifth, details and quality of developing theories will be distinguish between simple inquiry tasks and authentic inquiry. There are two aspects of developing a theory including level of theory and coordinating results from multiple studies. Level of theory, in simple inquiry tasks, students focus on directly observable empirical phenomena but they do not concern with constructing explanation as theory. By contrast, authentic inquiry concerned with providing evidence for a theory or development of theoretical mechanisms. Coordinating results from multiple studies, scientists coordinate results from many different types of studies conducted at different levels of analysis when they develop theories. In simple inquiry tasks, students are seldom asked to perform multiple studies on the same topic. Finally, the quality of studying research reports, scientists read the literature to learn standard procedures for choosing experimental parameters. In simple inquiry task, students do not study a body of research that has passed review by experts in the field.

\subsection{Epistemology of Scientific Inquiry}

Epistemology refers to people's basic beliefs about what knowledge is and when it should be changed. It indicates that there are some fundamental differences in epistemology authentic science tasks and simple inquiry tasks. These differences should be considered because students who learn about scientific reasoning through simple inquiry tasks may learn a nonscientific epistemology. Chinn \& Malhotra (2002) discussed various aspects of differences of epistemology in simple inquiry tasks and authentic scientific inquiry. These aspects included purpose of research, theorydata coordination, theory-ladenness of methods, responses to anomalous data, nature of reasoning, and social construction of knowledge.

Purpose of research, in real science, the goal of study is to develop and purify theoretical models in response to evidence. But, the goal of most simple inquiry tasks is only to uncover easily observable regularity or the salient structure of objects and not to generate theories about underlying mechanisms. Theory-Data Coordination, scientists study scientific research within chaos of data and theories. But, simple inquiry provides that science is a discipline that uses simple, reasoning patterns that are not applicable in other human endeavors, where data are messy. Theory-Ladenness of Methods, in authentic science, the methods are partly theory laden. There is no such interdependence between theory and method in simple inquiry tasks. Methods are assumed to be consistent if directions are properly followed. Therefore, students have no chance to construct an epistemology in which reflection on methods is important. Responses to 
Anomalous Data, because the set-up for simple inquiry tasks is so straightforward, if the students obtain anomalous data, the only rational response to the anomalous data is to change their hypothesis. In authentic scientific research, however, there are many different valid responses to anomalous data. Nature of Reasoning, simple inquiry tasks require the use of simple, often algorithmic strategies of reasoning. By contrast, reasoning in real science involves uncertain judgments and heuristics. Scientists may be unsure about every aspect of drawing inferences from experiments. Social Construction of Knowledge, another feature of the epistemology of authentic science is the construction of scientific knowledge through social processes and institutions. School science captures some aspects of the social construction of scientific knowledge (Chinn \& Malhotra, 2002).

\section{Methodology}

Methodology is qualitative research. The research will interpret teacher existing aspects of providing scientific inquiry activities through framework of Chinn \& Malhotra (2002) epistemology and cognitive processes of scientific inquiry.

\subsection{Participants}

Participants included 15 science pre-service teachers who enrolled for teaching practices in schools for one year, in Thailand. These pre-services have planned to provide scientific inquiry activities for science teaching and learning when they are teaching in schools.

\subsection{Data collection}

The questionnaire of Providing Activities for Scientific Inquiry (QASI) and interviewing were tools for interpreting science pre-service teacher existing ideas of providing activities for scientific inquiry. The QASI provided three open-ended questions about computer-supported for scientific inquiry in order to probe their ideas of inquiry in aspects of epistemology and cognitive processes. These included:

- How can we organize activities for scientific inquiry in Physics teaching and learning?

- How activities for science learning could generate students' learning about cognitive processes of scientific inquiry (generating research questions, designing studies, making observations, explaining results, developing theories, and studying research reports)?

- How activities for science learning could generate students' learning about constructing or developing scientific knowledge (purpose of research, theory-data coordination, theory-ladenness of methods, responses to anomalous data, nature of reasoning, social construction of knowledge)? QASI.

Then, the interviewing was carried out in order to further probe what pre-service exactly mean or respond to the

\subsection{Data Analysis}

Participants' responding was categorized into different existing ideas of providing activities for scientific inquiry. Chinn \& Malhotra (2002) epistemology and cognitive processes of scientific inquiry was referenced as expected ideas of providing activities for scientific inquiry.

\section{Findings and Discussion}

Science pre-service teachers considered how to organize computer-supported in science teaching for scientific inquiry. It indicated that most of them held existing ideas about computer-supported for simple scientific inquiry. Their ideas of computer-supported were provided for motivation of science learning, scientific model, remote learning, simulation for abstract concepts or dangerous experiments, database, instructional media, and flipped learning. These could be viewed as below some of existing ideas:

Use computer as instructional media such as simulation in order to foster students to understand scientific concepts. Or, use computer as database or searching for scientific knowledge. (Prin, 4 April 2014)

Use computer as remote learning e.g. satellite learning. Computer-supported illustrates complex or abstract concepts.

And, it also could simulate some phenomena or dangerous experiments e.g. nuclear reaction. (Mas, 2 April 2014) 
Computer could help us to provide information (data, pictures, sound, vdo, report, and so on) into the web. Then, students could study science or laboratory anytime and anywhere. (Bell, 4 April 2014).

Develop the learning unit depending on students interesting and capability. Use CAI to learn science. (Supatta, 4 April 2014).

Pre-service teachers' ideas seemed to lack of providing activities for scientific inquiry. However, some parts of their ideas could be counted into some aspects of cognitive processes and epistemology of scientific inquiry as follow:

\title{
4.1 Existing ideas about aspects of cognitive processes for providing scientific inquiry activities
}

It found that the most of participants perceived few aspects of cognitive process of scientific inquiry as showed in Table 1. Interestingly, it seemed that they have no ideas to organize the computer-supported for scientific inquiry in the way of developing theories. They aware of computer-supported could be organized for science inquiry in some aspects. It is only simple scientific inquiry. Number of them perceived that computer-supported could help making observation. However, their making observation would be only counted for transforming observations. Cognitive processes of inquiry on aspects of making observations, explaining results, studying research reports and designing studies were mentioned in their explanation. Even though, their ideas could be interpreted into some aspects of cognitive process of scientific inquiry, they also misunderstood in some issues of scientific inquiry e.g. making observations, and explaining results. Examples of pre-service teachers' existing ideas as below.

Table 1: Existing ideas about aspects of cognitive processes in using computer-supported for scientific inquiry

\begin{tabular}{lcc}
\hline Aspects of cognitive processes & Frequency $(\mathrm{N}=15)$ & Percents \\
\hline Generating research questions & 5 & 33.33 \\
Designing studies & 4 & 26.67 \\
Making observations & 9 & 60.00 \\
Explaining results & 2 & 13.33 \\
Developing theories & 0 & 0.00 \\
Studying research reports & 2 & 13.33 \\
\hline
\end{tabular}

Prin pre-service teachers' ideas of providing activity for science learning could be interpreted his cognitive processes of inquiry in three aspects including making observations, explaining results, studying research reports. His idea about explaining results was provided only aspect of transforming observations which refer to one or more rounds of data transformation. He mentioned as below:
We can use computer as instructional media. Students could observe clearly experiment through computer. And, computer could be used to show the relationship between velocity, distance / displacement, and time.
Computer is a key of searching information. Students could find the interesting research in order to develop their hypothesis and experiment design. (Prin, 4 April 2014)

Mas pre-service teachers' ideas could refer to cognitive processes of inquiry in two aspects including generating research questions and designing studies. She thought that computer could engage students to the issues and problem as her ideas below:

\begin{abstract}
Students could interact to the learning unit in the computer and feedback. They could study the unit again and again through the computer eg. CAl. The graphic, animation, and sound could motivate students to meet the issues or research problems. These problems allow students to engage to scientific inquiry. (Mas, 4 April 2014)
\end{abstract}

Lompad pre-service teachers'existing ideas revealed that he could not provide computer-supported for generating research question. He perceived only computer for presentation and computing machine as his ideas below. Instead, the computer could be used for further understand data and formulate evidences.

We can provide scientific inquiry through computer based. The advantages of computer-supported, students could solve high level of computation, construct graph and diagram, and find information. Students could provide interesting presentation by using computer. (Lompad, 4 April 2014)

However, some of them seemed to he have no ideas to use computer-supported for scientific inquiry. Bell preservice teacher thought that cognitive process of inquiry could be read from sentences or pictures provided in the 
websites rather than constructing from human endeavors during inquiry tasks. As he explained as below:

Students could learn and study scientific process skills (e.g. generating research questions, designing studies, making observations, explaining results, developing theories, and studying research reports) via websites or follow some scientists' inquiry. (Bell, 4 April 2014).

\subsection{Existing ideas about aspects of epistemology for providing scientific inquiry activities}

The findings indicated that participants have some perceived about epistemology of scientific inquiry when they showed the ideas of providing computer-supported for science teaching and learning. Only three of six aspects of epistemology of scientific inquiry were found from science pre-service teachers' ideas. These included responses to anomalous data, purpose of research, and theory-data coordination as showed in Table 2. The examples of pre-service teachers' ideas about using computer-supported for scientific inquiry were provided as below.

Table 2: Existing ideas about aspects of epistemology in using computer-supported for scientific inquiry

\begin{tabular}{lcc}
\hline Aspects of cognitive processes & Frequency $(\mathrm{N}=15)$ & Percents \\
\hline Purpose of research & 7 & 46.67 \\
Theory-data coordination & 6 & 40.00 \\
Theory-ladenness of methods & 0 & 00.00 \\
Responses to anomalous data & 3 & 20.00 \\
Nature of reasoning & 0 & 0.00 \\
Social construction of knowledge & 0 & 0.00 \\
\hline
\end{tabular}

Prin pre-services teachers' ideas of providing activities showed that he held idea of responses to anomalous data. It is one aspect of epistemology of scientific inquiry. His idea is below:

Students could find information from various sources. It is searching information skills and select data to provide evidences. (Bell, 4 April 2014)

Mas pre-service teacher's idea revealed that she consider that students need to understand the research purpose of research, then they will know what they should observe through experiments or simulation. Students would know to refines evidences. Her ideas as below:

Using computer based for science teaching could motivate students to learn. Animation, light, color, and sound will motivate students to ask questions. These questions will generate ideas of finding solutions through observation, experiment, computer simulation and so on. When students tried to find some solutions, they have chanced to develop scientific skills. (Mas, 4 April 2014)

Lompad pre-service teacher's ideas reflected that he held idea of theory-data coordination.

His explanation could be interpreted that he aware of giving students chance to generate scientific knowledge from data to theories. It showed existing idea about relationship of theories and data as his ideas below:

When students have chance to inquiry through computer based, they will perceive the relationship between inquiry for knowledge and using computer. They could be able to construct knowledge after analyze data and simulation. (Lompad, 4 April 2014)

Interestingly, epistemology of scientific inquiry in aspects of theory-ladenness of methods, nature of reasoning, social construction of knowledge seemed to has difficulty of organizing in Thai science classroom. These three aspects related to argumentation in scientific classroom. This finding consistency to previous studies of Thai classroom (Ketsing\& Roadrangka, 2010).;Yuenyong \& Narjaikaew, 2009) that discussed that Thai science classroom needs to support argumentation in classroom.

\section{Conclusion}

It showed that most of science pre-service teachers considered computer-supported activities in order to provide motivation of science learning, scientific model, remote learning, simulation for abstract concepts or dangerous 
experiments, database, instructional media, and flipped learning. However, most of them lack of how to provide computer-supported in science teaching as authentic inquiry. Few aspects of cognitive process of scientific inquiry had showed when they gave the ideas of using computer-supported for science teaching. Only three of six aspects of epistemology of scientific inquiry were found from science pre-service teachers' ideas. This suggests that epistemology and cognitive process of scientific inquiry should be concerned when teachers develop computer-supported for science learning.

\section{References}

Asay, L.D. \& Orgill, M.K. (2010) Analysis of Essential Features of Inquiry Found in Articles Published in The Science Teacher, 19982007, Journal of Science Teacher Education, 21:57-79

Abd-El-Khalick, F., Boujaoude, S., Duschl, R., Lederman, N. G., Mamlock-Naaman, R., Hofstein, A., et al. (2004). Inquiry in science education: International perspectives, Science Education, 88, 397- 419.

Crawford, B. A. (2000). Embracing the essence of inquiry: New roles for science teachers, Journal of Research in Science Teaching, 37 , 916-937.

Ketsing, J. \& Roadrangka, V. (2010). Case study of science teachers' understanding about teaching for scientific inquiry. Kasetsart Journal (social science), 31(1): $1-16$.

Krajcik, J., Blumenfeld, P. C., Marx, R. W., Bass, K. M., Fredricks, J., \& Soloway, E. (1998). Inquiry in project-based science classrooms: Initial attempts by middle school students, The Journal of the Learning Sciences, 7, 313-350.

Lee, H., \& Songer, N. B. (2003). Making authentic science accessible to students, International Journal of Science Education, 25, 923948.

Chinn, C.A, \& Malhotra, B. A. (2002). Epistemologically Authentic Inquiry in Schools: A Theoretical Framework for Evaluating Inquiry Tasks, Science Educaiton, 86: 175 - 218.

Chen, W.; Looi, C.; Xie, W. \& Wen, Y. (2013). Empowering argumentation in the science classroom with a complex CSCL environment. In S. C., Tan et al. (Eds.), Proceedings of the 21st International Conference on Computers in Education. Indonesia: Asia-Pacific Society for Computers in Education

Schwarz, C. V., \& White, B. Y. (2005). Metamodelling knowledge: Developing students' understanding of scientific modeling, Cogintion and Instruction, 23(2), 165-205.

Goldsmith, D. J. (2007). Enhancing learning and assessment through e-Portfolios: A collaborative effort in connecticut. New Directions for Student Services, (119), 31-42.

Minocha, S., \& Thomas, G.P. (2007). Collaborative learning in a wiki environment: Experiences from a software engineering course. New Review of Hypermedia and Multimedia, 13(2), 187-209.

Mishra, P., \& Koehler, M. J. (2006). Technological Pedagogical Content Knowledge: A Framework for Teacher Knowledge, Teachers College Record, 108(6), 1017 - 1054.

Yuenyong, C. \& Narjaikaew, P. (2009). Scientific Literacy and Thailand Science Education, International Journal of Environmental and Science Education, 4 (3): 335 - 349. 